\title{
Synthesis of a high-quality NaP zeolite from epidesmine by a hydrothermal method
}

\author{
XIANGJIAN MENG ${ }^{1}$, XIAOWEI GUO ${ }^{1}$, YIJIAN ZHONG ${ }^{2}$, YINCHANG PEI ${ }^{2}$, NANCHUN CHEN ${ }^{1, *}$ \\ and QINGLIN XIE ${ }^{2}$ \\ ${ }^{1}$ College of Material Science and Engineering, Guilin University of Technology, Guilin 541004, \\ People's Republic of China \\ ${ }^{2}$ College of Environmental Science and Engineering, Guilin University of Technology, Guilin 541004, \\ People's Republic of China \\ *Author for correspondence (cnc@ glut.edu.cn)
}

MS received 8 October 2018; accepted 7 May 2019

\begin{abstract}
Epidesmine as a silicon source was used to synthesize $\mathrm{NaP}$ zeolite by a hydrothermal method. Parameters such as $\mathrm{SiO}_{2} / \mathrm{Al}_{2} \mathrm{O}_{3}$ and $\mathrm{H}_{2} \mathrm{O} / \mathrm{Na}_{2} \mathrm{O}$ molar ratios, reaction temperatures and reaction times were investigated for regulating the purity of the final product. The samples were characterized by X-ray diffraction, infrared spectroscopy and scanning electron microscope. The experimental results evidenced that a high-quality $\mathrm{NaP}$ zeolite was obtained at $\mathrm{SiO}_{2} / \mathrm{Al}_{2} \mathrm{O}_{3}$ and $\mathrm{H}_{2} \mathrm{O} / \mathrm{Na}_{2} \mathrm{O}$ molar ratios of 3.7 and 55, respectively, and at a temperature of $95^{\circ} \mathrm{C}$ for $6.5 \mathrm{~h}$ of ageing. The BET surface area and total pore volume of the powders were $17.1359 \mathrm{~m}^{2} \mathrm{~g}^{-1}$ and $0.006845 \mathrm{~cm}^{3} \mathrm{~g}^{-1}$, and the pore size was $\sim 3.2 \mu \mathrm{m}$.
\end{abstract}

Keywords. Epidesmine; NaP zeolite; hydrothermal method; molar ratios; reaction temperature; reaction time.

\section{Introduction}

Zeolites are kinds of crystalline solids with an extending three-dimensional framework of silicon and aluminium tetrahedra linked by sharing oxygen atoms. Well-defined channels, morphology as well as crystal size of these zeolites have a significant role in industries [1]. NaP is a kind of most interesting structured zeolite with two sets of intersecting channels and its structure is called 'Gismondine' (GIS). The NaP zeolite can be used not only as a cation exchanger and an adsorbent, but also it has been found to have widespread application in the purification of metal ions, separation of gases and as a carrier of antibacterial agents [2].

In recent years, the preparation of synthetic zeolites has been increasing by using natural minerals, such as clinoptilolite, pyrophyllite, mordenite, chabazite, epidesmine, etc., because the preparation of chemical reagents was expensive [3]. A hydrothermal method enables effective solvability of water and the solubility and reactivity of the reactants for the synthesis of zeolite, rearranging and dissolving the initial primary gel, which increases the crystallization rate. This method is beneficial to control the grain size and morphology of the product crystal [4,5].

Epidesmine is considered as one of the most abundant natural minerals in Guangxi. As a type of inorganic mineral, epidesmine possesses good thermostability, acid stability and high quality of whiteness. One of the effective utilization is to convert epidesmine into zeolitic materials and synthesizing zeolites is considered as an environmental friendly application of epidesmine [6].

In the present investigation, we attempted the hydrothermal synthesis of $\mathrm{NaP}$ under controlled different conditions. Optimization of crystallization conditions was adapted through variation of the following parameters: $\mathrm{SiO}_{2} / \mathrm{Al}_{2} \mathrm{O}_{3}$ and $\mathrm{H}_{2} \mathrm{O} / \mathrm{Na}_{2} \mathrm{O}$ molar ratios, ageing times and ageing temperatures.

\section{Experimental}

\subsection{Materials and chemicals}

Epidesmine (table 1) from the Guangxi province of China, hydrochloric acid ( $\mathrm{HCl}, 36-38 \mathrm{wt} \%)$ from XilongGuangdong, sodium hydroxide $(96 \mathrm{wt} \% \mathrm{NaOH})$ from Xilong-Guangdong and sodium aluminate $\left(45 \%\right.$ of $\left.\mathrm{Al}_{2} \mathrm{O}_{3}\right)$ from Guangfu-Tianjin were obtained.

Experimental apparatus: DF-101S Hot type thermostatic magnetic stirring apparatus from Yuhua Instrument Limited, Liability Company, Gongyi city, Henan province; TDZ5WS multi-tube frame automatic balancing centrifuge from Xiangyi Lab instrument exploitation limited company, Hunan province; PHB-3 pen type meter from Sanxin instrument and meter plant, Shanghai province and electric heating constant temperature drying oven from Yuejin medical apparatus factory, Shanghai province, were obtained. 
Table 1. Chemical composition of epidesmine (\%).

\begin{tabular}{lllllllllll}
\hline $\mathrm{SiO}_{2}$ & $\mathrm{Al}_{2} \mathrm{O}_{3}$ & $\mathrm{CaO}$ & $\mathrm{K}_{2} \mathrm{O}$ & $\mathrm{Na}_{2} \mathrm{O}$ & $\mathrm{Fe}_{2} \mathrm{O}_{3}$ & $\mathrm{H}_{2} \mathrm{O}^{+}$ & $\mathrm{H}_{2} \mathrm{O}^{-}$ & $\mathrm{Si} / \mathrm{Al}$ & Loss on ignition & Total \\
\hline 58.76 & 14.13 & 8.8 & 0.11 & 0.18 & 0.44 & 16.87 & 1.25 & 3.529 & 17.79 & 100.1 \\
\hline
\end{tabular}

\subsection{Synthesis of NaP zeolite}

In the first step, epidesmine and $15 \%$ hydrochloric acid in a $1: 3$ ratio were mixed in a three-necked flask, a stirring bar was added into the solution and the solution was stirred at $150 \mathrm{rpm}$ for $2 \mathrm{~h}$. Reaction temperature was $90^{\circ} \mathrm{C}$. Then, the mixture was washed with distilled water up to $\mathrm{pH}$ 6-7 and dried at $60^{\circ} \mathrm{C}$ for $12 \mathrm{~h}$ to obtain a precursor.

In the second step, $3 \mathrm{~g}$ of the precursor was placed in a reactor, then sodium aluminate, sodium hydroxide and distilled water were mixed in the three-necked flask according to $\mathrm{SiO}_{2} / \mathrm{Al}_{2} \mathrm{O}_{3}=3.3-3.7, \mathrm{Na}_{2} \mathrm{O} / \mathrm{SiO}_{2}=1.1$ and $\mathrm{H}_{2} \mathrm{O} / \mathrm{Na}_{2} \mathrm{O}=$ 45-55. Hydrothermal crystallization was continued under continuous magnetic stirring for $6 \mathrm{~h}$ at $95^{\circ} \mathrm{C}$.

In the third step, the synthesized zeolite was filtered, washed thoroughly with deionized water to remove unreacted and water-soluble components, and then, dried overnight at $60^{\circ} \mathrm{C}$ for $12 \mathrm{~h}$ to obtain the $\mathrm{NaP}$ zeolite. This was characterized by means of different instrumental techniques.

\subsection{Characterization}

The crystal structure of $\mathrm{NaP}$ zeolite was analysed by using an X-ray diffractometer (XRD) (X'Pert PRO, PANalytical, Almelo, Holland) using $\mathrm{CuK} \alpha$ radiation at a scanning rate of $10^{\circ} \mathrm{min}^{-1}$ and the $2 \theta$ range from 5 to $80^{\circ}$.

The presence of functional groups of $\mathrm{NaP}$ zeolite was analysed by using a Fourier transform infrared (FTIR) spectrophotometer (IRAffinity, Shimadzu, Japan) using $\mathrm{KBr}$ as a reference material in the range of $400-4000 \mathrm{~cm}^{-1}$ with a resolution of $0.5 \mathrm{~cm}^{-1}$.

The morphology of the NaP zeolite was investigated using a field emission scanning electron microscopic (FESEM) system (Hitachi, S-4800).

\section{Results}

\subsection{Effect of $\mathrm{SiO}_{2} / \mathrm{Al}_{2} \mathrm{O}_{3}$ ratios}

The characteristic peaks of the $\mathrm{NaP}$ zeolite at 12.5, 17.6, 21.7, 28.1 and $33.4^{\circ}$ [7] were identified in XRD patterns of zeolite powders (figure $1 \mathrm{~A}$ ) obtained in a $\mathrm{SiO}_{2} / \mathrm{Al}_{2} \mathrm{O}_{3}$ ratio ranging from 3.3 to 3.7 , indicating the formation of the $\mathrm{NaP}$ zeolite crystalline phase (JCPDS no. 71-0962) [8]. Besides, the characteristic peaks of quartz at 20.8 and $26.9^{\circ}$ were always existed in the three curves, correspondingly, the conventional step of alkali dissolution was skipped [9]. Notably, a diffraction peak of the $\mathrm{NaX}$ zeolite at $\mathrm{SiO}_{2} / \mathrm{Al}_{2} \mathrm{O}_{3}=3.3$ and 3.5 was also observed (figure 1A; a, b), indicating that the chemical compositions were analogous between the $\mathrm{NaP}$ zeolite and $\mathrm{NaX}$ zeolite. The $\mathrm{NaP}$ zeolite with higher purity was synthesized in a $\mathrm{SiO}_{2} / \mathrm{Al}_{2} \mathrm{O}_{3}$ ratio $=3.7$ (figure $1 \mathrm{~A} ; \mathrm{c}$ ).

Figure 1B depicts the IR spectra of the NaP zeolite synthesized from the hydrothermal process with variable $\mathrm{SiO}_{2} / \mathrm{Al}_{2} \mathrm{O}_{3}$ ratios. The strong vibration at around $1000 \mathrm{~cm}^{-1}$ was observed and the intensity of this band declined with an increase in $\mathrm{SiO}_{2} / \mathrm{Al}_{2} \mathrm{O}_{3}$ ratio, which can be attributed to an increase in the number of $\mathrm{Al}-\mathrm{O}$ bonds [10]. The bands at 740 and $665 \mathrm{~cm}^{-1}$ are attributed to the Si-O and Al-O symmetrical stretching vibrations, respectively. $\mathrm{Si}-\mathrm{O}-\mathrm{Si}$ is responsible for the band at $600 \mathrm{~cm}^{-1}$. The band at $440 \mathrm{~cm}^{-1}$ is assigned to the tetrahedron bending vibration [11]. The bending vibration shifted from 450 (figure $1 \mathrm{~B}$; a, b) to $440 \mathrm{~cm}^{-1}$ (figure $1 \mathrm{~B}$; c) resulting in the disappearance of the $\mathrm{NaX}$ zeolite. These peaks were in accordance with those reported by Albert et al [12].

The morphological evaluation and particle size of the $\mathrm{NaP}$ zeolite with different $\mathrm{SiO}_{2} / \mathrm{Al}_{2} \mathrm{O}_{3}$ (3.3, 3.5 and 3.7) molar ratios were investigated by FESEM (figure 1C). The octahedral structures of the NaX zeolite were observed (figure $1 \mathrm{C}$; $\mathrm{a}, \mathrm{b}$ ), but these crystal structures are incomplete, which means that the complete $\mathrm{NaX}$ zeolite cannot be produced under this condition. The crystals of the NaP zeolite have a rounded shape, which is similar to the ones observed in previous research [13]. The diameter of the spherical particle was $1.5 \mu \mathrm{m}$ (figure $1 \mathrm{C}$; c).

\subsection{Effect of $\mathrm{H}_{2} \mathrm{O} / \mathrm{Na}_{2} \mathrm{O}$ ratios}

Alkalinity plays an important role in the synthesis of the zeolite by impacting polymerization aluminate and aluminosilicate oligomers, controlling the state of silicate anions and maintaining the balance of ingredient in the system, ensuring the formation of particles and promoting the crystallization process $[14,15]$. When the $\mathrm{H}_{2} \mathrm{O} / \mathrm{Na}_{2} \mathrm{O}$ ratio increased from 45 to 55 , the crystallinity of the product gradually increased (figure 2A; a, b and c). However, as the ratio increased from 55 to 60 , the crystallization of the $\mathrm{NaP}$ zeolite slightly diminished and the characteristic peaks of the $\mathrm{NaX}$ zeolite were observed (figure 2A; d), so the alkalinity too high or too low will affect the formation and stability of the crystal [16], suggesting that $\mathrm{H}_{2} \mathrm{O} / \mathrm{Na}_{2} \mathrm{O}=55$ was suitable condition for the synthesis of the $\mathrm{NaP}$ zeolite.

SEM observations of the samples after hydrothermal treatment with $\mathrm{H}_{2} \mathrm{O} / \mathrm{Na}_{2} \mathrm{O}=45,50,55$ and 60 are presented 

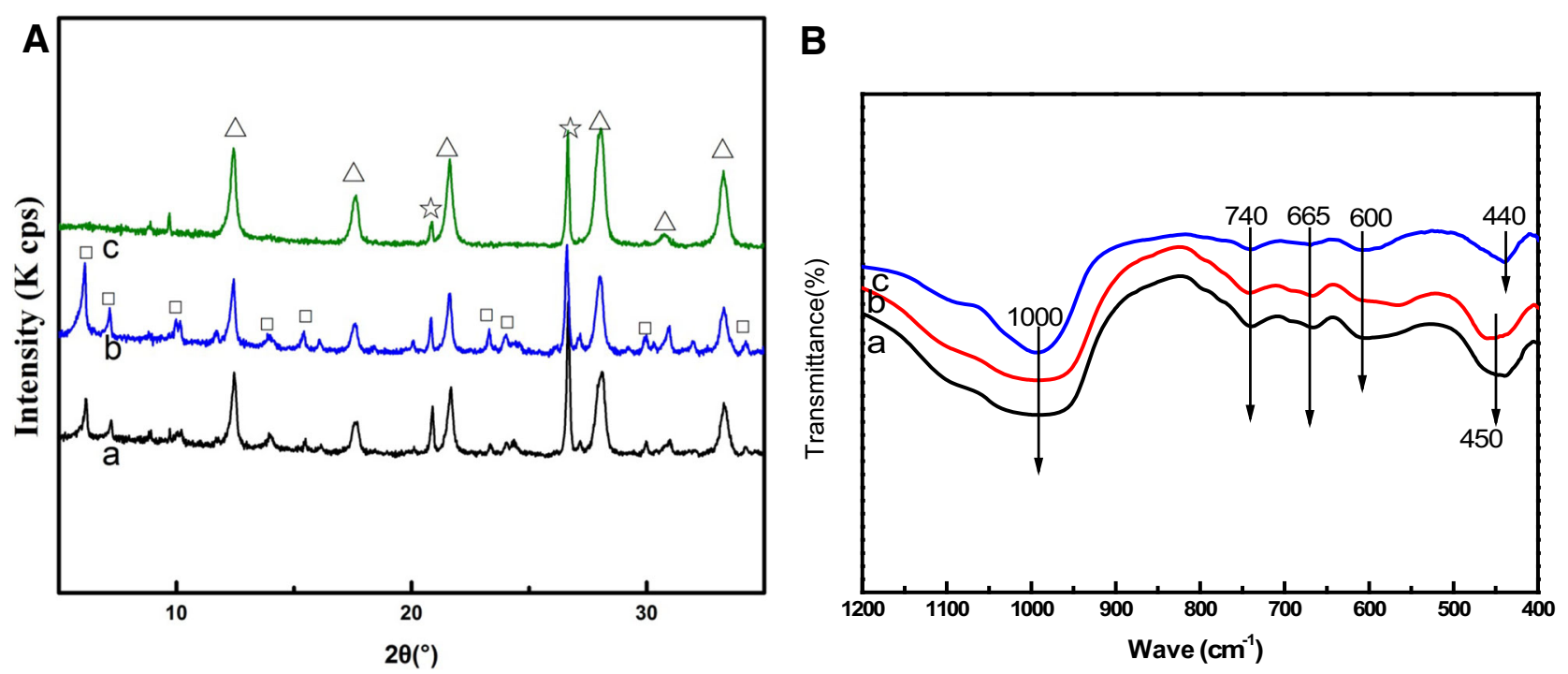

C
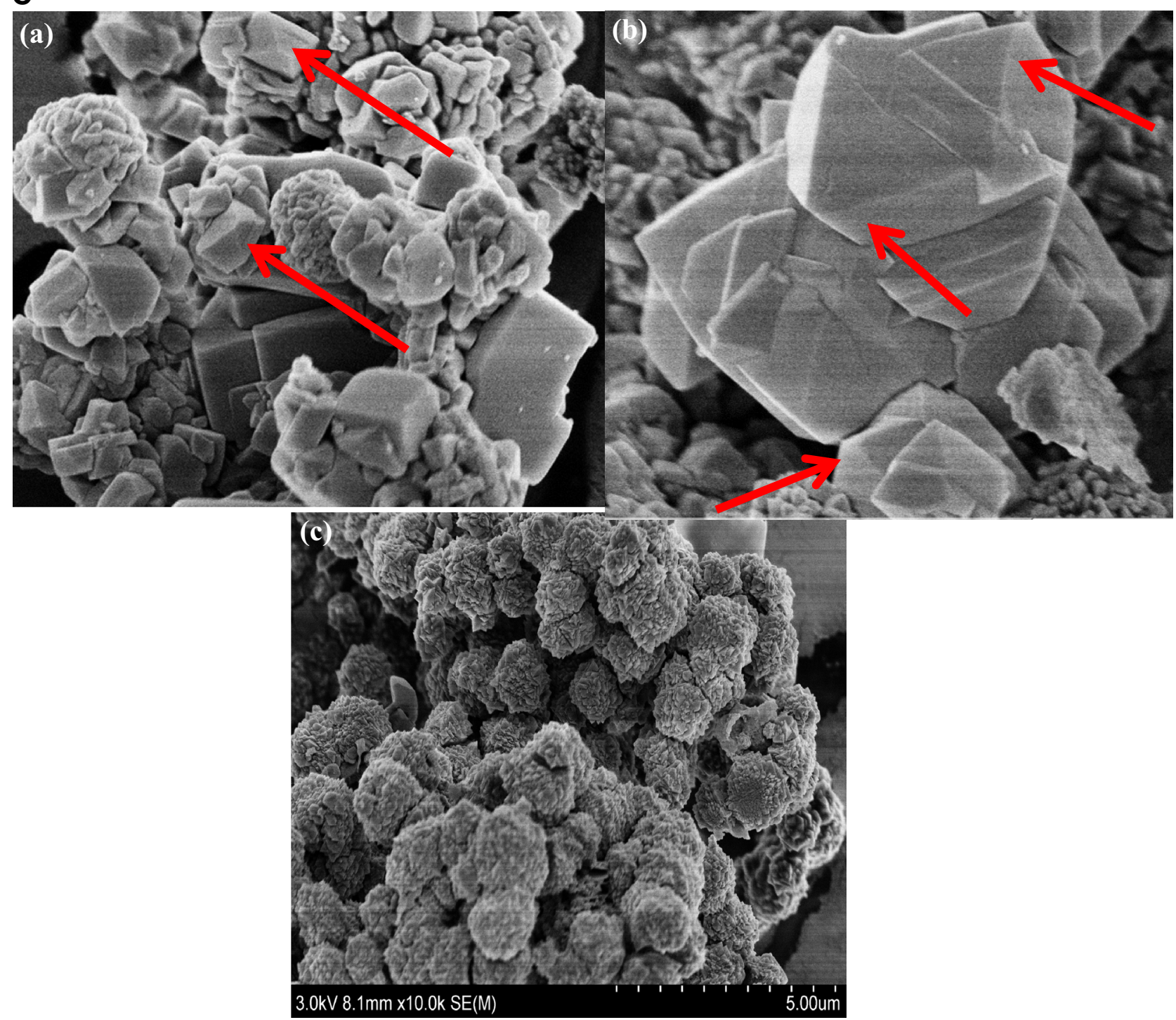

Figure 1. (A) XRD pattern, (B) FTIR and (C) SEM images of the NaP zeolite synthesized with different $\mathrm{SiO}_{2} / \mathrm{Al}_{2} \mathrm{O}_{3}$ ratios (a. 3.3, b. 3.5 and c. 3.7). 


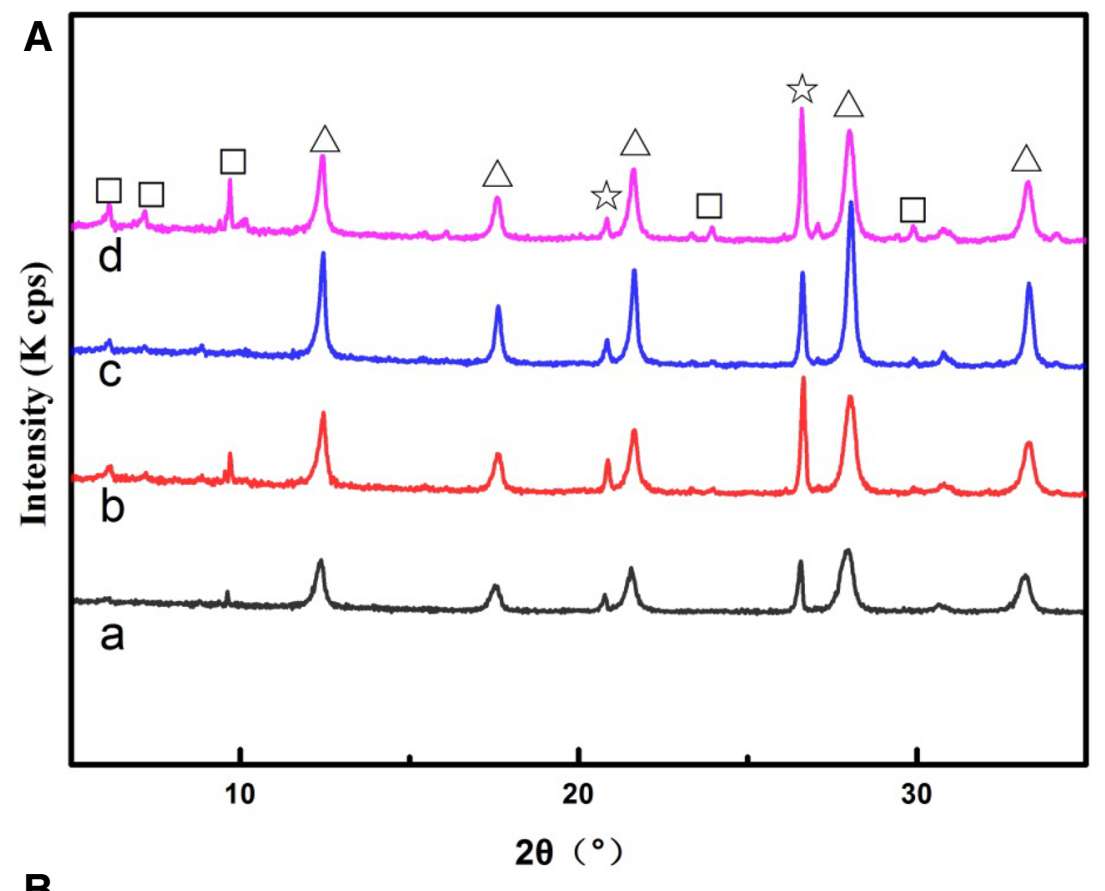

B

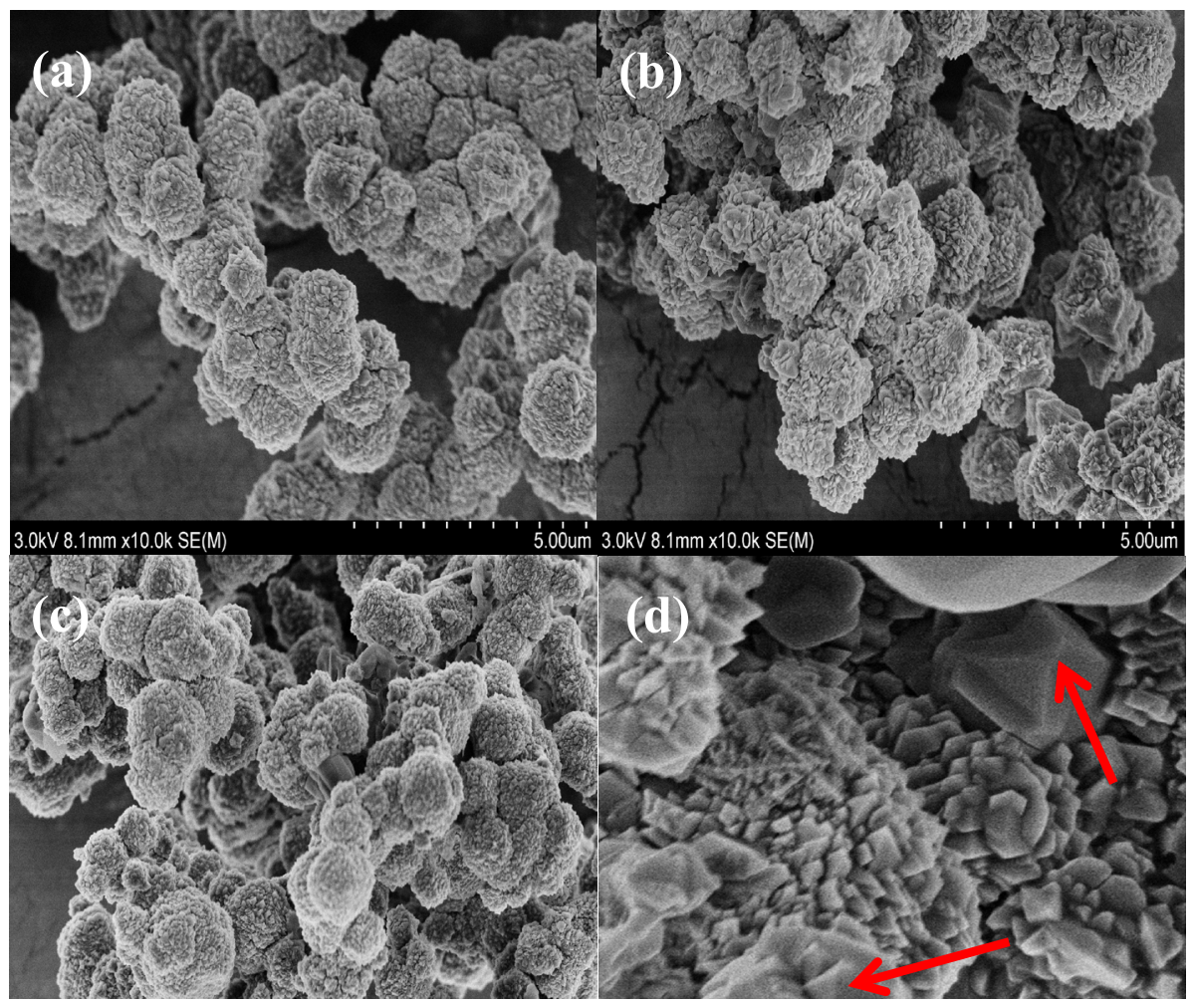

Figure 2. (A) XRD patterns and (B) SEM images of the NaP zeolite synthesized with different $\mathrm{H}_{2} \mathrm{O} / \mathrm{Na}_{2} \mathrm{O}$ ratios (a. 45 , b. 50 , c. 55 and d. 60 ).

in figure $2 \mathrm{~B}$. Compared to figure $2 \mathrm{~B} ; \mathrm{a}, \mathrm{b}, \mathrm{c}$ and $\mathrm{d}$, figure $2 \mathrm{~B}$; d presents an octahedral morphology [17], confirming the results of XRD measurements (figure 2A; d). SEM images (figure 2B; c) showed that the $\mathrm{NaP}$ zeolite has a fine crystal when $\mathrm{H}_{2} \mathrm{O} / \mathrm{Na}_{2} \mathrm{O}=55$.

\subsection{Effect of hydrothermal temperature}

The NaP zeolite was obtained at four different temperatures $80,85,90$ and $95^{\circ} \mathrm{C}$, and the hydrothermal sample is shown in figure 3A. Only amorphous substance is observed in 

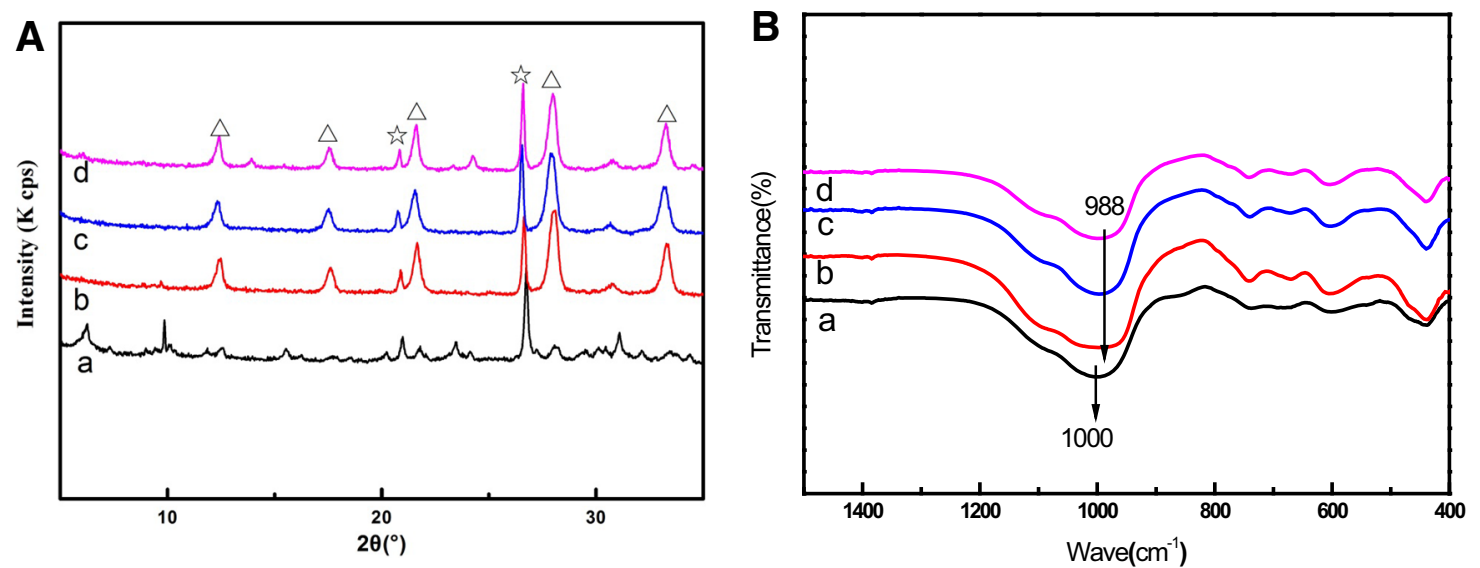

C
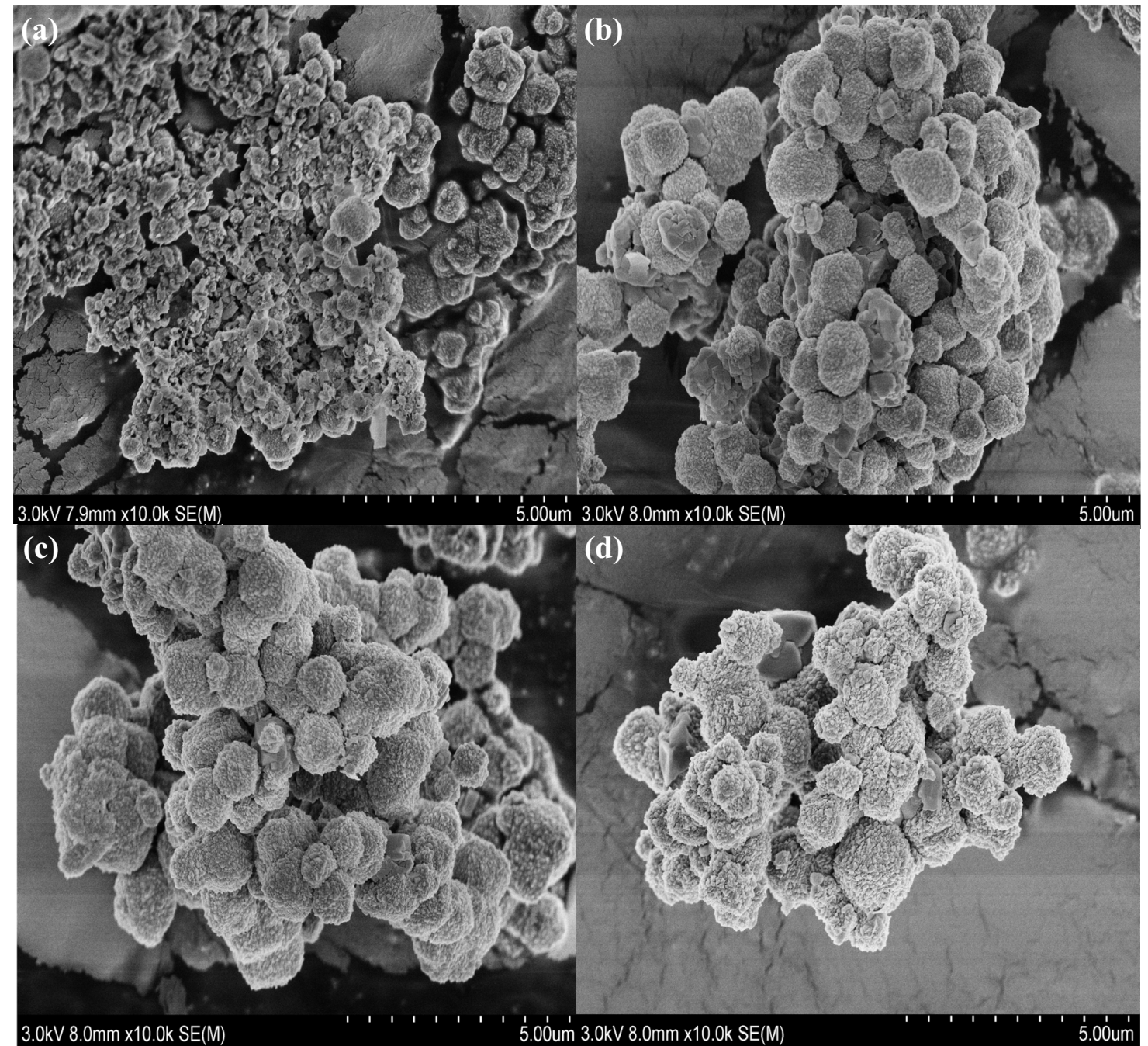

Figure 3. (A) XRD patterns, (B) FTIR and (C) SEM of the NaP zeolite synthesized at different temperatures (a. 80, b. 85 , c. 90 and d. $95^{\circ} \mathrm{C}$ ).

figure $3 \mathrm{~A}$; a, it was the incomplete dissolution of the $\mathrm{Si}$ and $\mathrm{Al}$ atoms from the precursor [18].
The characteristic peak of XRD does not change significantly, when the temperature was gradually increased 


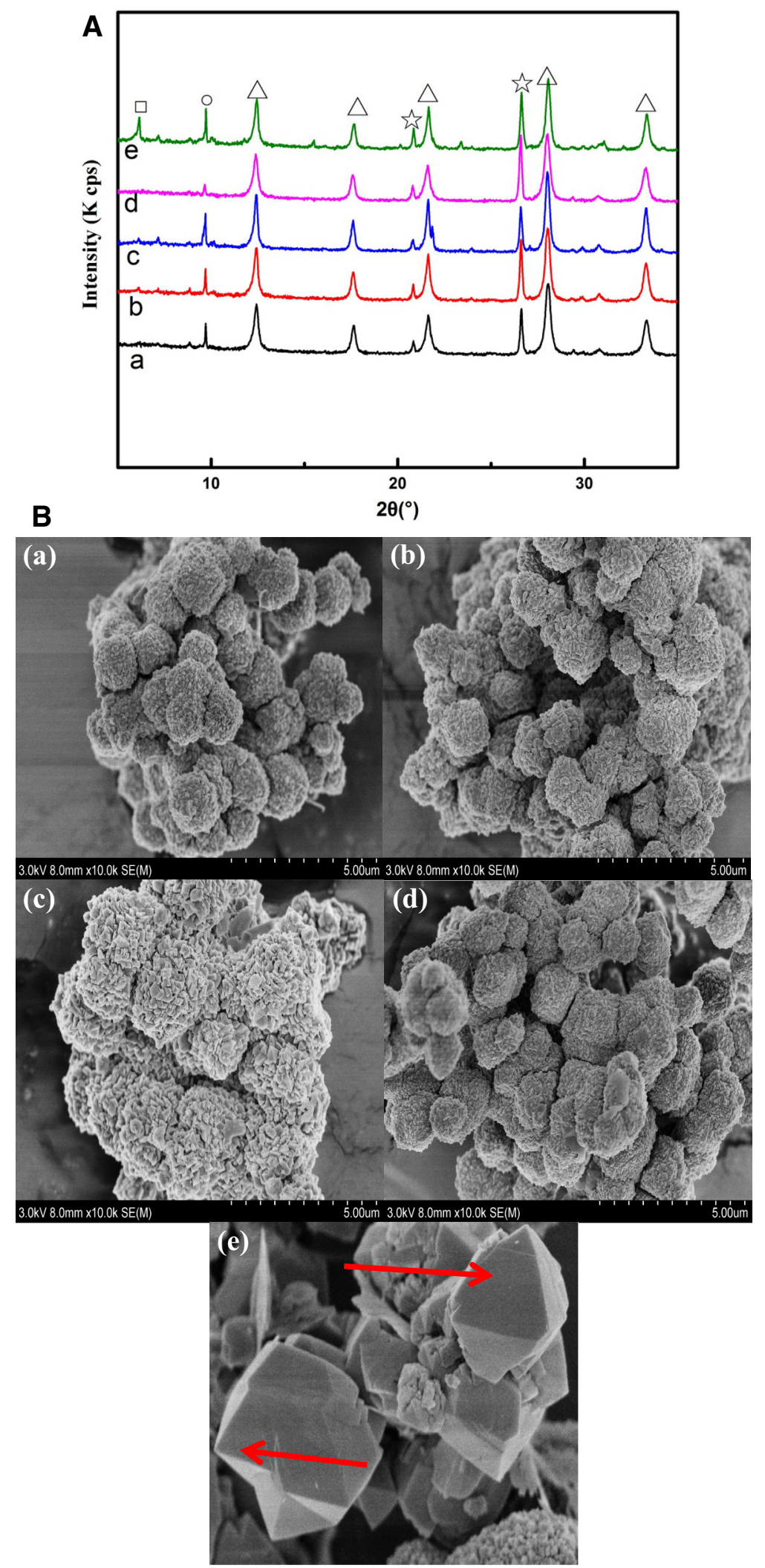

Figure 4. (A) XRD patterns and (B) SEM of the NaP zeolite synthesized at different times (a. 5 , b. 5.5 , c. 6.0 , d. 6.5 and e. 7.0 h). 
from 85 to $95^{\circ} \mathrm{C}$ (figure $3 \mathrm{~A}$; b, c and $\mathrm{d}$ ). This result indicated that the $\mathrm{NaP}$ zeolite was completely formed and crystal transformation was not observed when the material ratio was controlled.

Figure 3B presents the IR spectra of the zeolite. The peaks at $400-1500 \mathrm{~cm}^{-1}$ were significantly weakened at $80^{\circ} \mathrm{C}$ (figure $3 \mathrm{~B}$; a) from the infrared contrast chart, indicating that the $\mathrm{NaP}$ zeolite has not been synthesized at this temperature. The band at $1000 \mathrm{~cm}^{-1}$ is assigned to a $\mathrm{Si}-\mathrm{O}$ or Al-O asymmetric stretch. By increasing the hydrothermal treatment temperature from 80 to $95^{\circ} \mathrm{C}$, the peak position shifted from high to low wavenumber (1000-988 $\mathrm{cm}^{-1}$ ), which meant that the $\mathrm{Si}-\mathrm{O}$ bond was weakened due to a part of the $\mathrm{O}$ atom of the $\mathrm{Si}-\mathrm{O}$ bond combining with the $\mathrm{Al}$ atom.

The SEM images of the synthesized products are shown in figure $3 \mathrm{C}$. The particles of the product are small and irregular at $80^{\circ} \mathrm{C}$ (figure $3 \mathrm{C}$; a), proving that the nucleus of the $\mathrm{NaP}$ zeolite was not formed [19]. The crystal grown rapidly at $85^{\circ} \mathrm{C}$ (figure $3 \mathrm{C}$; b), leading to the $\mathrm{NaP}$ zeolite with a spherical shape was observed [20], and the crystal morphology did not change as the temperature increases from 85 to $95^{\circ} \mathrm{C}$ (figure $3 \mathrm{C} ; \mathrm{b}, \mathrm{d}$ ). Particles with an average diameter of $1.5 \mu \mathrm{m}$ are presented in figure $3 \mathrm{C}$; $\mathrm{d}$, and they have a larger particle size compared to the particle size shown in figure $3 \mathrm{C}$; b, c.

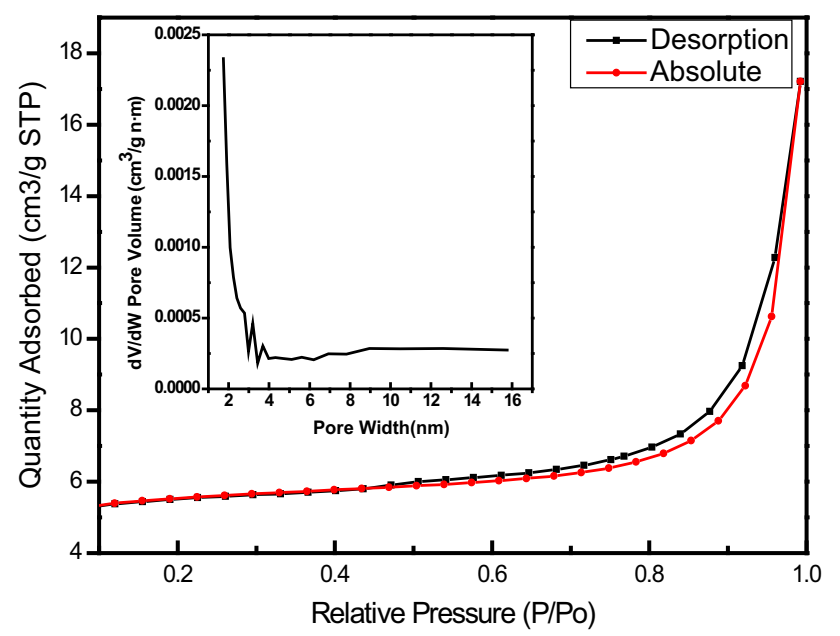

Figure 5. $\mathrm{N}_{2}$ adsorption-desorption isotherms of the NaP zeolite prepared with $\mathrm{SiO}_{2} / \mathrm{Al}_{2} \mathrm{O}_{3}=3.7, \mathrm{Na}_{2} \mathrm{O} / \mathrm{SiO}_{2}=1.1$ and $\mathrm{H}_{2} \mathrm{O} / \mathrm{Na}_{2} \mathrm{O}=55$ at $95^{\circ} \mathrm{C}$ for $6.5 \mathrm{~h}$. The inset shows the pore-size distributions of the $\mathrm{NaP}$ zeolite.

\subsection{Effect of hydrothermal time}

The effect of the hydrothermal time on the crystallization of the $\mathrm{NaP}$ zeolite under similar conditions, i.e., $\mathrm{SiO}_{2} / \mathrm{Al}_{2} \mathrm{O}_{3}=$ 3.7, $\mathrm{Na}_{2} \mathrm{O} / \mathrm{SiO}_{2}=1.1$ and $\mathrm{H}_{2} \mathrm{O} / \mathrm{Na}_{2} \mathrm{O}=55$, respectively, were determined. The XRD powder patterns of samples at $95^{\circ} \mathrm{C}$ for different crystallization times $(5,5.5,6,6.5$ and $7 \mathrm{~h})$ are shown in figure $4 \mathrm{~A}$. The obvious characteristic peaks of the $\mathrm{NaP}$ zeolite and heterocrystalline stilbite at $9.68^{\circ}$ were observed in five-diffraction patterns (figure 4A); however, it could be clearly observed that the crystal diffraction intensity of stilbite is low and is shown in figure $4 \mathrm{~A}$; $\mathrm{d}$. When the hydrothermal time increased to $7 \mathrm{~h}$, the $\mathrm{NaX}$ zeolite and stilbite are observed in figure 4A; e [21]. Mixed crystals appeared when the reaction time was prolonged and the crystallization time should be controlled at $6.5 \mathrm{~h}$ for the preparation of the NaP zeolite.

Figure 4B shows the microstructure of the products prepared at different hydrothermal times. The regular shape of the $\mathrm{NaP}$ zeolite has been formed when the hydrothermal time was $5 \mathrm{~h}$. The size of the NaP zeolite increased and the surface became rough in the product as the temperature increased to $6 \mathrm{~h}$. When the hydrothermal time is $7 \mathrm{~h}$, the octahedral angle of the $\mathrm{NaX}$ zeolite became clear and the size was uniform (2 3 $3 \mu \mathrm{m})$ [22]. The products were identified as NaP zeolite from XRD analysis. In figure $4 \mathrm{~B}$; $d$, the size of the samples was larger and more uniform compared to others, the average particle size of the NaP zeolite was about $1.5 \mu \mathrm{m}$.

\subsection{Surface area texture}

Figure 5 shows the $\mathrm{N}_{2}$ adsorption-desorption isotherms of the zeolite at liquid nitrogen temperature $(77 \mathrm{~K})$. In mesoporous zeolites, the sorption behaviour is a function of fluid wall interaction strength and the attractive interactions between the fluid molecules [23]. NaP zeolite samples show a type IV isotherm characteristic of solids with a predominantly mesoporous channel (figure 5). The mesopore region represents a relative pressure range of $0.5-0.95$, the hysteresis loop of the sample is H3-type, which is a typical system with a 'bottle' pore distribution [24]. Besides, the pore size distribution found by the Barrett-Joyner-Halenda method as shown in figure 5 (inset), exhibited the main mesoporous distribution. The sample exhibits a broad pore size distribution of $2-16 \mathrm{~nm}$ and is mainly concentrated at $3.2 \mathrm{~nm}$. Table 2 shows that the BET surface area is $17.1359 \mathrm{~m}^{2} \mathrm{~g}^{-1}$ and the total pore volume is $0.006845 \mathrm{~cm}^{3} \mathrm{~g}^{-1}$.

Table 2. Surface characteristics of the $\mathrm{NaP}$ zeolite at $\mathrm{SiO}_{2} / \mathrm{Al}_{2} \mathrm{O}_{3}=3.7, \mathrm{Na}_{2} \mathrm{O} / \mathrm{SiO}_{2}=1.1$ and $\mathrm{H}_{2} \mathrm{O} / \mathrm{Na}_{2} \mathrm{O}=55$ at $95^{\circ} \mathrm{C}$ for $6.5 \mathrm{~h}$.

\begin{tabular}{lcccc}
\hline Sample & BET surface area & $t$-plot micropore area & $t$-plot external surface area & $t$-plot micropore volume \\
\hline NaP zeolite & $17.1359 \mathrm{~m}^{2} \mathrm{~g}^{-1}$ & $13.2565 \mathrm{~m}^{2} \mathrm{~g}^{-1}$ & $3.8794 \mathrm{~m}^{2} \mathrm{~g}^{-1}$ & $0.006845 \mathrm{~cm}^{3} \mathrm{~g}^{-1}$ \\
\hline
\end{tabular}




\section{Conclusion}

The NaP zeolite was synthesized using epidesmine as a silicate source via a simple hydrothermal process. The effects of $\mathrm{SiO}_{2} / \mathrm{Al}_{2} \mathrm{O}_{3}$ ratios, $\mathrm{H}_{2} \mathrm{O} / \mathrm{Na}_{2} \mathrm{O}$ ratios, crystallization times and crystallization temperatures in zeolites on the crystalline were investigated. The experimental results illustrated that the $\mathrm{NaX}$ zeolite gradually disappeared as the $\mathrm{SiO}_{2} / \mathrm{Al}_{2} \mathrm{O}_{3}$ ratios increased from 3.3 to 3.7 by the hydrothermal method at $95^{\circ} \mathrm{C}$ for $6.5 \mathrm{~h} . \mathrm{SiO}_{2} / \mathrm{Al}_{2} \mathrm{O}_{3}$ and $\mathrm{H}_{2} \mathrm{O} / \mathrm{Na}_{2} \mathrm{O}$ ratios were found to play an important role in the zeolite structure and composition. The $\mathrm{NaP}$ zeolite with high crystalline was obtained at $\mathrm{H}_{2} \mathrm{O} / \mathrm{Na}_{2} \mathrm{O}=55$ and reaction time $=6.5 \mathrm{~h}$. Furthermore, a well-developed $\mathrm{NaP}$ zeolite could be obtained after hydrothermal treatment at $85^{\circ} \mathrm{C}$ for $6.5 \mathrm{~h}$. The formation of the target product $\mathrm{NaP}$ zeolite was accompanied by the appearance of the stilbite after $5 \mathrm{~h}$ of hydrothermal treatment at $95^{\circ} \mathrm{C}$ and the $\mathrm{NaX}$ zeolite appeared when the time increases to $7 \mathrm{~h}$. Besides, a long-crystallization time results in miscellaneous compounds being developed. Thus, the optimal synthesis conditions to obtain a NaP zeolite were $\mathrm{SiO}_{2} / \mathrm{Al}_{2} \mathrm{O}_{3}=3.7$ and $\mathrm{H}_{2} \mathrm{O} / \mathrm{Na}_{2} \mathrm{O}=55$ at $95^{\circ} \mathrm{C}$ for $6.5 \mathrm{~h}$. The NaP zeolite has a uniform mesoporous structure with a pore size of about $3.2 \mu \mathrm{m}$. The surface area is $17.1359 \mathrm{~m}^{2} \mathrm{~g}^{-1}$ and the total pore volume is $0.006845 \mathrm{~cm}^{3} \mathrm{~g}^{-1}$.

\section{Acknowledgements}

We acknowledge financial support from the National Natural Science Foundation of China (nos. 41662005, 51564008) and the Guangxi Natural Science Foundation (2015GXNSFAA139094).

\section{References}

[1] Pal P, Das J K, Das N and Bandyopadhyay S 2013 Ultrason. Sonochem. 20314

[2] Li J, Corma A and Yu J 2016 Cheminform. 467112
[3] Sánchez-Hernández R, López-Delgado A, Padilla I, Galindo R and López-Andrés S 2016 Microporous Mesoporous Mater. 226267

[4] Qiu X, Liu Y, Li D and Yan C 2015 J. Porous Mater. 22291

[5] Kotova O B, Shabalin I N, Shushkov D A and Kocheva L S 2016 Adv. Appl. Ceram. 115152

[6] Zou J, Guo C, Wei C, Li F and Jiang Y 2016 Mater. Trans. 172 121

[7] Behin J, Kazemian H and Rohani S 2016 Ultrason. Sonochem. 28400

[8] Du Y, Shi S and Dai H 2011 Particuology 9174

[9] Kong D S, Song S J, Wang Q and Zhang L C 2017 Bull. Chin. Ceram. Soc. $\mathbf{9 8} 699$

[10] Kazemian H, Naghdali Z, Kashani T G and Farhadi F 2010 Adv. Powder Technol. 21279

[11] Sharma P, Song J S, Han M H and Cho C H 2016 Sci. Rep. 6 22734

[12] Albert B R, Cheetham A K, Stuart J A and Adams C J 1998 Microporous Mesoporous Mater. 21133

[13] Sathupunya M, Gulari E and Wongkasemjit S 2002 J. Eur. Ceram. Soc. 222305

[14] Musyoka N, Petrik L, Gitari W, Balfour G and Hums E 2012 Environ. Res. Lett. 47337

[15] Chen Y, Xie C, Han H, Zhao F and Wang B 2015 Chem. J. Chinese Univ. 36229

[16] Zhou H, Xu T, Chen Y, Xie C and Song H 2016 Chin. J. Chem. Eng. 1282534

[17] Bortolatto L B, Santa R A A B, Moreira J C, Machado D B, Martins M A P M, Fiori M A et al 2017 Microporous Mesoporous Mater. 248214

[18] Askari S, Alipour S M and Halladj R 2013 J. Porous Mater. 20 285

[19] Huo Z, Xu X, Lv Z, Song J, Li Z, Wang Q et al 2013 J. Therm. Anal. Calorim. 111365

[20] Behin J, Bukhari S S, Kazemian H and Rohani S 2016 Fuel 171 195

[21] Ali I O, El-Sheikh S M, Salama T M, Bakr M F and Fodial M H 2015 Sci. China Mater. 58621

[22] Wajima T, Haga M, Kuzawa K, Ishimoto H, Tamada O, Ito K et al 2006 J. Hazard. Mater. 132244

[23] Persson A E, Schoeman B J, Sterte J and Otterstedt J-E 1994 Zeolites 14557

[24] Taguchi A and Schüth F 2005 Microporous Mesoporous Mater. 771 